\title{
Transplantation $^{8}$ LETTERS TO THE EDITOR \\ HETEROGENOUS DISTRIBUTION OF CHIMERISM PRODUCED BY RAT ORGAN AND BONE MARROW ALLOTRANSPLANTATION
}

We recently described a striking association of organ allograft acceptance and the quantity and quality of immunocytochemically detectable donor leukocyte chimerism caused by previous ("priming") transplants (1). In these experiments, $1.0 \mathrm{mg} / \mathrm{kg} /$ day tacrolimus on days $0-13$ and single supplemental doses on days 20 and 27 were given intramuscularly to Brown Norway $\left(\mathrm{BN}, \mathrm{RT} 1^{\mathrm{n}}\right)$ recipients of primary Lewis (LEW, RT $1^{1}$ ) orthotopic livers, bone marrow infusions, abdominally placed heart allografts (the Ono-Lindsey model [2]) and other kinds of organs and leukocyte suspensions. On day 100 , after a drug-free interval of 73 days, the liver, bone marrow, and heart recipients accepted "challenge" liver and cardiac allografts from LEW strain donors for another 100 days. At day 200, significant histopathologic findings of chronic rejection in the challenge hearts were absent, minimal, and most obvious in the animals originally primed with the livers, bone marrow, and hearts, respectively (1).

Although the results in this investigation correlated generally with the degree and kind of chimerism produced by the priming allograft, the substantial but incomplete tolerance at 100 days produced in primary heart recipients in whom donor leukocytes could no longer be found with immunocytochemical techniques prompted the following experiments. Hearts, livers, or bone marrow cells from male LEW donors were transplanted to female $B N$ recipients under the same conditions as reported previously, including the short course of tacrolimus. At 100 days, the animals were killed and their tissues were studied with polvmerase chain reaction (PCR) and Southern hybridization. using rat Y-chromosome isex determining region $\mathrm{Y}$ [SRY])-specific primers (3). This procedure allowed detection of small numbers of male cells (to $1 / 50,000$ recipient cells, $0.002 \%$ ) in female recipients.

Donor DNA was found in the spleen, native heart, liver, or thymus of the three heterotopic heart recipients treated by the previous protocol (group 1, Table 1). Five of the 14 samples, but only one in five from the spleen and lymph nodes, were positive. In two of the three animals, donor DNA was present at more than one site. As reported before (1), no cells were detected with immunocytochemistry.

Three additional heart recipients (group 2) also were administered $180 \mu \mathrm{g} / \mathrm{kg} /$ day rmGM-CSF $(\mathrm{n}=2)$ or $250 \mu \mathrm{g} / \mathrm{kg} /$ day rhG-CSF $(n=1)$ for 14 days (day $0-13$ ). Four of six spleen or lymph node samples contained donor DNA (Table 1) and two of these (in a GM-CSF-treated animal) were positive with immunocytochemistry. Although not conclusive, the greater yield from the spleen and lymph nodes of the growth factortreated heart recipients was consistent with our speculation (1) that the better control of rejection in liver transplant recipients treated with G-CSF reported by Foster et al. (4) was due to an augmentation of spontaneous chimerism.

In rats submitted to liver replacement (group 3 ), three of six samples from the spleen or a lymph node tested positive for donor DNA (Table 1). In animal 357, the donor DNA was found only in the bone marrow (footnote $d$ in table). Donor bone marrow infusion (group 4) produced the most ubiquitous chimerism of any kind of allograft with or without growth factor therapy: 13 of 15 samples were positive $1 \mathrm{Ta}$ ble 1 ).

T.миц.: 1. Semquantitation of $Y$-chromosome-detected chimerism in recipient tissues 100 davs after LEW male to BN female heart. liver. and bone marrow transplantation

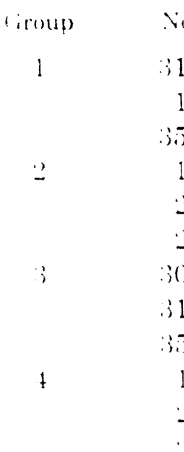

$\times 11$
311
14
356
19
26
23
309
310
357
16
20
24

$$
\begin{gathered}
\text { Procedure } \\
\text { HTX } \\
\text { HTX } \\
\text { HTX } \\
\text { HTX - (i.MCSF } \\
\text { HTX + G.MCSF } \\
\text { HTX - GCSF } \\
\text { ()LTX } \\
\text { ()LTX } \\
\text { 1)LTX } \\
\text { BMTX } \\
\text { BMTX - G.MCSF } \\
\text { BMTX-GCSF }
\end{gathered}
$$

spleen

$1 / 1.000-10.000$

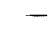

$1 / 10.000$

$1 / 10.000$

$-$

$1.1 .000-10.000$

$1 / 1.000-10.000$

$1 / 10.000$

$1.1 .000-10.000$

$1 / 1.000-10.000$

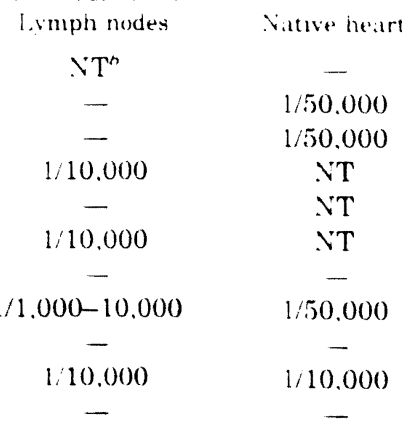

$1 / 10.000$

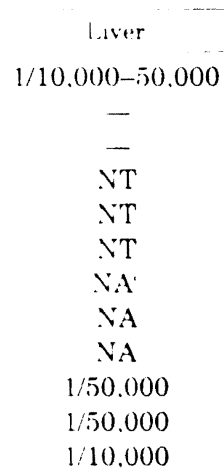

Thymus

$-$

$1 / 50.000$

$\mathrm{NT}$

NT

NT

$-$

-

$1 / 50.000$

$1 / 10.000$

$1 / 10.000$

Procedures: HTX. heart transplantation: ()LTX. liver transplantation: BMTX. bone marrow transplantation

$\therefore T$. not tested

VA. not applicable.

Donor DNA was tound in this animals bone marrow 
The heterogenous distribution of donor DNA was reminiscent of that in our original clinical studies (5) in which 27 (of 27) human organ recipients had microchimerism 10-22 years after liver or kidney transplantation. However, the donor leukocytes were frequently found in only one or two of the three systematically sampled sites (blood, skin, and lymph node), with similar irregular distribution in other tissues not routinely obtained (heart, intestine, and bone marrow). Studies in rats $(1,6)$ and mice $(7)$ also have underscored the warning that the absence of chimerism cannot be inferred from negative test results in limited tissue and blood samples. The best evidence is that the long survival of an organ allograft under the conditions of clinical transplantation, and in analogous animal models, means that chimerism is present. Failure to demonstrate it implies an incomplete search.

\author{
NORIKO MURASE \\ ANTHONY J. DEMETRIS \\ ATHANASSIOS C. TSAMANDAS \\ QING YE \\ THOMAS E. STARZL ${ }^{1}$ \\ Pittsburgh Transplantation Institute \\ University of Pittsburgh Medical Center \\ Pittsburgh, Pennsylvania 15213
}

${ }^{1}$ Address correspondence to: Thomas E. Starzl, $\mathrm{MD}, \mathrm{PhD}$, Pittsburgh Transplantation Institute, University of Pittsburgh Medical Center, 3601 Fifth Avenue, 4C Falk Clinic, Pittsburgh, PA 15213.

\section{REFERENCES}

1. Murase N, Starzl TE, Tanabe M, et al. Variable chimerism, graft versus host disease, and tolerance after different kinds of cell and solid organ transplantation from Lewis to Brown-Norway rats. Transplantation 1995; 60: 158.

2. Ono K, Lindsey ES. Improved technique of heart transplantation in rats. J Thorac Cardiovasc Surg 1969; 57: 225.

3. Tashiro H, Fukuda Y, Kimura A, et al. Monitoring for rejection and engraftment following rat orthotopic liver transplantation by polymerase chain reaction. Transplantation 1994; 58: 745.

4. Foster PF, Mital D, Sankary HN, et al. The use of granulocyte colony stimulating factor after liver transplantation. Transplantation 1995; 59: 1557.

5. Starzl TE, Demetris AJ, Trucco $M$, et al. Cell migration and chimerism after whole-organ transplantation: the basis of graft acceptance. Hepatology 1993; 17: 1127.

6. Demetris AJ, Murase N, Fujisaki S, Fung JJ, Rao AS, Starzl TE. Hematolymphoid cell trafficking, microchimerism, and GVHD reactions after liver, bone marrow, and heart transplantation. Transplant Proc 1993; 25: 3337.

7. Qian S, Demetris AJ, Murase N, Rao AS, Fung JJ, Starzl TE. Murine liver allograft transplantation: tolerance and donor cell chimerism. Hepatology 1994; $19: 916$.

\section{HEPATITIS C VIRUS AND TRANSPLANTATION}

The recent study of the impact of hepatitis $\mathrm{C}$ infection on the outcome of renal transplantation by Pereira et al. (Transplantation 1995: 60(8): 799) raises the contentious issue of whether patients who harbor the hepatitis $C$ virus should undergo renal transplantation at all. Little mention, however, is made in this heterogenous group of 23 hepatitis C-positive recipients of the presence at the time of transplantation of active liver disease as indicated by liver biopsy or levated liver enzymes. In a retrospective study from our own single institutional experience, where 38 renal allograft recipients were hepatitis $C$ positive at the time of surgery, all patients had normal liver enzymes (Kazi et al., Dig Dis Sci 1994: 39: 961). In eight of these patients overt liver disease developed after transplant. compared with 14 of the 214 non-hepatitis $\mathrm{C}$ patients. In two of the eight patients who received transplants, histological evidence of chronic active hepatitis developed, but no recipient has succumbed to prorressive liver disease (100\% follow-up). Chronic active hepatitis developed in six of the 14 non-hepatitis $C$ patients, and two died of cirrhosis: 10 of these 14 patients were hepatitis $B$ positive. Our data therefore suggested that hepatitis C-positive potential renal allograft recipients with normal liver enzymes at the time of transplantation were at low risk for the development of chronic liver disease in the posttransplant period. In light of these findings, perhaps Dr. Pereira and colleagues would be willing to reanalyze their data to look at the outcome of the subset of hepatitis C-positive patients whose hepatitis appears to be quiescent, i.e., with a normal liver biopsy or liver enzymes at the time of transplantation? If indeed these latter recipients are at low risk, then the proscription against renal transplantation suggested by Pereira's group might not be applicable to this subset of patients.

\section{RAYMOND POLLAK ${ }^{1}$ \\ ENRICO BENEDETTI \\ Division of Transplantation \\ Department of Surgerv \\ Universitv of Illinois at Chicago \\ Chicago, Illinois}

${ }^{1}$ Address correspondence to: Raymond Pollak, MB, Division of Transplantation. Department of Surgery, University of Illinois at Chicago, 801 South Pauline Street, C'hicago, IL 60612.

\section{IN SLPPORT OF THE FINDINGS OF CHRISTOPHER F. BRYAN ET AL.}

We have read with interest the article by Dr. Bryan and (0)-workers 11) regarding the detection of HLA IgG class I alloantibodies (aAb) using enzyme-linked immunoassays (EIA) (2). We have similarly performed an evaluation of the PRA-STAT EIA kit Imanufactured by SangStat Medical Corp. and marketed by Nextran, an affiliate of Baxter Healthcare, and compared it with the standard "NIH" C. dependent cytotoxicity (CDC) and antiglobulin (AHG) CDC PRA screening methods (.3). We find that in our laboratories as well, this commercial EIA kit cannot reliably detect HLA class I aAb.

In our study, $30 \mathrm{HLA}$-specitic class I aAb ( 3 IgM and 27 IgG $\mathrm{aAb}$ ) of reagent typing quality and 150 sera, including blind duplicates and dilutions obtained from renal transplant can- 